\title{
THE UNBEARABLE LIGHTNESS OF PRESCRIBING GROWTH HORMONE
}

\author{
Ljiljana Šaranac
}

Faculty of Medicine, University of Niš, Niš, Serbia

\begin{abstract}
Short stature is the most visible and prominent physical characteristic and one of the commonest reason for referral to pediatric endocrinologist. It is assumed as disabling condition with psychosocial consequences that seeks treatment. Behind short stature severe pathology could be hidden, although not necessarily of endocrine origin. Even in the new millennium, many diagnostic pitfalls and dilemmas persist in confirmation of growth hormone deficiency (GHD), the first indication that fits in endocrine paradigm: to replace the missing hormone. In 1985 FDA approved recombinant human $G H(h G H)$ as the treatment of pediatric patients who have growth failure due to inadequate secretion of endogenous GH. Availability of hGH in unlimited amounts enhanced the number of indications of GH use. Pediatric endocrinologist started to promote and to apply use of hGH for height in short, but otherwise healthy children, with hormonal normalcy. Reasonable criticism of such praxis arises in the light of recent safety alerts. The unbearable lightness of prescribing growth hormone to every apparently or really short child is reaching epidemic progress in Serbia. When authorities in this low income country (estimated as developing), approved hGH for use in SGA (small for gestational age) children, use and misuse of hGH exploded. Socially acceptable height, the term applied by some endocrinologists actually means that society does not accept short people. The pharmaceutical companies go even further offering, besides growth acceleration, better and brighter future for potential patients, in whom the self-confidence is measured by centimeters of height. However, benefits of such treatment on quality of life were never confirmed. Children with severe growth failure and documented GHD should be treated undoubtedly, but use of hGH for height, so called cosmetic endocrinology, needs critical appraisal. Children and their parents should be informed about height prediction and long-term consequences.
\end{abstract}

Key words: Growth Hormone Use, GHD, SGA, ISS, Short Stature, Cosmetic Endocrinology.

"Even in the most wary mariner may easily lose his way as he seeks to steer his bark amid the glandular temptations whose siren voices have proved the downfall of many who have gone before" wrote Boyd in 1943, according to Bailey [1]

\section{Introduction}

Growth failure due to growth hormone deficiency (GHD) is the easiest endocrine disorder to treat and the hardest to diagnose [2]. Short stature is the most visible and prominent physical characteristic. It is assumed as disabling condition with psychosocial consequences that seeks treatment. However, benefits of such treatment on quality of life were never confirmed. Behind short stature severe pathology could be hidden, although not necessarily of endocrine origin. Neglecting growth monitoring in primary and secondary health care centers results in delayed diagnosis of severe diseases or plenty of inappropriate referrals. A high frequency of diagnostic delays is reported for so-called classical target condi-

Correspondence to: Ljiljana Šaranac, M.D., Ph.D.

Faculty of Medicine, 81 Zoran Đinđić Blvd., 18000 Niš, Serbia

Phone: +381628242161

E-mail: endoljilja@yahoo.com

Received January $19^{\text {th }}, 2019$ tions, such as Turner syndrome, GHD, Crohn's disease, celiac disease and cystic fibrosis. On the other hand, inadequate growth monitoring can result in unnecessary diagnostic cumbersome investigation [3].

It was hoped that the discovery by Evans and Long in 1921 of a mammalian pituitary gland extract capable of producing growth in laboratory animals, would solve the problem of short stature in children. However, it was not until 1956, when growth hormone from human pituitary glands was extracted by Raben. In 1957, the effective treatment was available for the small percentage of short children with growth hormone deficiency. GH substitution therapy in hypopituitary man, published in NEJM by Raben in 1962 was an example of the first personalized therapy use [4]. In late 1984, a 20-year-old man who was previously treated with cadaveric pitGH died from Creutzfeldt-Jakob disease, which led to abrupt withdrawal of pitGH in United States. In 1985 FDA approved recombinant human $\mathrm{GH}(\mathrm{hGH})$ as the treatment of pediatric patients who have growth failure due to inadequate secretion of endogenous $\mathrm{GH}$, and shortly after hGH was approved in Europe. Availability of hGH in unlimited amounts since 1985, enhanced the number of indications of its use (Table 1). 
Table 1 Approved Indications for hGH use in EU, Serbia and USA

\begin{tabular}{ll}
\hline European Union and Serbia & United States of America \\
\hline - GHD in children and adults & - GHD* in children and adults \\
- Turner Syndrome & - Turner Syndrome \\
- Small for Gestational Age & - Small for Gestational Age \\
- Prader-Willi Syndrome & - Prader-Willi Syndrome \\
- Chronic Renal Failure & - Chronic Renal Failure \\
& - Idiopathic Short Stature \\
& (ISS) \\
& -SHOX deficiency \\
& - Noonan Syndrome \\
& - Short Bowel Syndrome \\
& - AIDS wasting in Adults \\
\hline
\end{tabular}

* GHD - Growth Hormone Deficiency

For prescribers the availability of abundant amounts of recombinant human growth hormone led to introduction of hGH for height treatment, and not only for substitution of missing hormone or restoring physiological hormonal normalcy. The diagnosis of GHD was widen and more inclusive by arbitrary raising cutoff diagnostic values in provocative testing. The old diagnostic criterion, commonly used in the past for GHD in children was peak level during stimulation less than $3 \mathrm{ng} / \mathrm{mL}$ (very restrictive and limited to severe or persistent and true GHD, also called „certain" or „definitive GHD"). Paradoxically, as $\mathrm{GH}$ assays grew more specific, criterion for failing a $\mathrm{GH}$ stimulation test grew even more generously. Cutoffs rose from 3 to $7 \mathrm{ng} / \mathrm{mL}$ to the current $10 \mathrm{ng} / \mathrm{mL}$ level [5]. MRI findings are more cosistent with clinical characteristics of GHD and more predictive of response to hGH therapy than are peak GH responses in provocative testing. Structural abnormalities of the hypothalamic-pituitary region have been described on MRI in up to $90 \%$ of patients with multiple pituitary hormone deficiency (MPHD), suggesting that brain MRI may represent the first-line investigation for diagnosing GHD, especially in infancy and early childhood $[5,6]$. In 2003, the FDA expanded hGH use to the treatment of ISS (Idiopathic short stature), also called nonGH-deficient short stature, defined by height standard deviation score (SDS) $<-2.25$ ( $<1.2$ nd percentile). The height cutoff of $-2.25 \mathrm{SD}$ (1.2nd percentile) corresponds in adults to $160 \mathrm{~cm}$ for men and $150 \mathrm{~cm}$ for women [7-9]. The concept of of ISS is controversial, artificial, arbitary and heterogeneous, including normal and patients with pathology, but having one thing in common: our ignorance to obtain an etiopathogenic diagnosis [5, 8].

Short stature is one of the commonest reasons for referral to most pediatric endocrine clinics. The unbearable lightness of prescribing growth hormone to every apparently or really short child is reaching epidemic progress in Serbia. When authorities in this low income country (estimated as developing), approved hGH for use in SGA (small for gestational age) children, use and misuse of GH exploded. Without any serious estimation of pro and contra reasons, many times under pressure of parents, children get GH. Even children with failure to thrive because of gluten intolerance or caloric restriction due to poverty, get hGH therapy, as result of superficial investigation or misdiagnosis. Medical doctors without any international reference travel across the planet sponsored by pharmaceutical industry, get a big honoraria promoting that bigger is better and even healthier. But, children are not so happy with their daily injections. The height gain is variable as myriad of reasons influencing growth are in game. The average increase in adult height after multiple years of treatment ranged from 3.56 to $7.56 \mathrm{~cm}$. The question arises whether an average height gain of $5 \mathrm{~cm}$ should be considered as satisfactory taking into account the cost of $70000 \$$ for such gain (or 10,000\$-60,000\$ per patient year), besides pain of daily injections and discomfort of frequent periodic clinical investigations [9-11].

Thus the arrival of recombinant hGH shifted basic endocrine paradigm in endocrinology: to substitute deficient hormone and to suppress hyperfunction or; physiological hGH replacement to pharmacological hGH therapy for height enhancement [9]. This new statement is not free of potential severe consequences. As key opinion leader, Allen DB emphasized that there is increasing uncertainty about the real benefits and potential risks of hGH therapy for many thousands of short, but otherwise healthy children $[9,10]$. Applying hGH in children with hormonal normalcy as in ISS is common decision of parents and doctors. Laventhal et al. [11] describe this complex relationship as a tango for three (patients and their parents, doctors willing to prescribe and regulators ready to approve and to pay for its use). As De Vries noticed [12] they do not mention a fourth dancer: the pharmaceutical companies. Marketing strategies of these companies result in intense and close doctor-industry relationships and could influence doctors' prescribing practices [13-15]. Prescribers of hGH became "investigators" whose institution or even they personally, received per-patient compensation for detection, treatment and follow-up and reporting hGHtreated patients $[10,15]$. Recent articles published in Hormone Research in Pediatrics and in The New England Journal of Medicine summarize all important issues in this area. They attracted my attention by reasonable criticism of cosmetic endocrinology and also revealed new, brilliant explanation of such phenomenon, lurking behind the scene $[9,10,15]$.

\section{GH Effects beyond Height}

Many teenagers with GHD have poor bone strength, fatigue and lack of stamina, as well as depression, lack of concentration, poor memory and anxiety problems. As a mother of one GH deficient child said: "GHD isn't just about growth, as lack of growth hormone impacts the child in many ways, such as lack of strength and they can find it difficult to keep up physically with their peers. It impacts the child self-esteem as they are often treated as being much younger, because of their size" [16]. GH treatment allows the child to growth to their genetic potential. Majority of short people have life- 
long problem in finding appropriate clothes and shoes, or purchase in children's stores, because shops do not carry their size [17]. Severe short stature is no doubt, physically debilitating requiring special accommodations for reaching shelves or driving [15].

Components of GH-IGF-1 axis make an important contribution to the development, function, regeneration and neuroprotection of the CNS. GH plays well established roles in neurogenesis, axonal elongation and formation of oligodendrocytes, astrocytes and glial cells, as well as in angiogenesis, synaptogenesis, and synaptic transmission and prevention of neuronal apoptosis $[18,19]$. Indeed in patients with congenital classic triade syndrome, we were informed by parents about improvement in maturity and positive behavioral changes. Namely, true GHD shows not only impairment in psychological well-being but also defects in attention, memory and executive function, with evidence of improvement in cognitive function after $\mathrm{GH}$ replacement [18-20]. This effect is more evident in "definite GHD" and it is obtained at least partly by stimulating T4 to T3 conversion with great impact on neurodevelopment.

The discontinuation of treatment in adolescents with GHD after completion of linear growth may be associated with adverse effects on body composition, lipid profile, and cardiac morphology [18].

While people tend to attribute significantly less favorable characteristic to short persons, research repeatedly in majority of studies fails to detect an excess of psychosocial adaptation problems among shortstatured youths [15]. Socially acceptable height, the term used by some endocrinologists actually means that society does not accept short people. The pharmaceutical companies go even further and offer, not only growth acceleration and improvement of final height as result of GH therapy, but also better and brighter future for potential recipients in whom the self-confidence is measured by centimeters of height. As Allen DB noticed: „It is too good to be all good" [15]. Is hGH ,,panacea or Pandora's box?" he asked [21]. A trend of exaggeration of hGH use for height, ,heightism" [21,22] remainds me of sociopathic virus of fear of aging (,,ageism"), also imported in Europe from USA. Justification of hGH use for height needs confirmation that this treatment is safe and free of serious short term and long term adverse events. These phantastic references also led me to publications of Samaras concerning of logevity regarding height. Within generally healthy conditions short people live longer. Most centenarians tend to be short or small. It is best to be short and lean and to restrict protein intake. One mechanism supporting the "shorter and smaller is better" thesis is somatic cell duplication potential. Bigger bodies use up more cell replications during their maturation, because they contain more cells. It takes more cells to build and maintain a bigger body, and more cells increase the risk in cancer in taller people. Big people cost more [23-25]. Disruption of the GH-IGF-1 axis may result in increased longevity [26].

\section{Safety Issues}

Occurrence of adverse events during hGH treatment as intracranial hypertension, glucose intolerance, a slipped capital femoral epiphysis is well known and its incidence is low [27]. Physician's discussions with families must involve honest and realistic appraisal of treatment expectations for height gain [11]._It is worrisome that serious adverse events usually are not discussed. Post marketing studies sponsored by pharmaceutical companies, manufacturers of hGH so far reported only short term adverse events. Short term effects are not long term effects, more precisely; long term effects are still unknown. This statement does not refer to $\mathrm{GH}$ deficient subjects on hGH substitution therapy, but to hGH applied for height in healthy children.

When the announcement on increased mortality in $\mathrm{GH}$ treated individuals reached the headlines a lot of anxiety was produced in professional and scientific community as well as in GH recipients and their families [28]. The study on the Safety and Appropriateness of GH treatments in Europe (SAGhE study) announced that that the observation of long-term outcomes of children treated with hGH between 1985 and 1996, revealed a significant excess mortality (93 deaths vs. 70 expected from an age-matched population in France) [29]. Additionally a follow-up of 30000 low-risk children treated with hGH between 1980 and 1990 in 8 European countries, who had reached 18 years of age between 20092010 was performed. Patients were classified as low mortality risk if they were diagnosed as idiopathic GHD, SGA, or ISS without genetic syndrome or defects. Patients with renal failure, short stature syndrome, like Turner syndrome, and tumor survivors were excluded. A preliminary report from France on 6928 lowrisk children with mean follow-up of $17.3 \pm 4.1$ years from the start of therapy showed an increase in the overall standardized mortality ratio. The increase in allcause mortality was associated with a higher hGH dose of $>50 \mu \mathrm{g} / \mathrm{kg} /$ day, but not with the severity of GHD or the duration of total $\mathrm{GH}$ exposure. Increased mortality rate was due to bone tumors, cardiovascular events and cerebrovascular hemorrhage [28-30]. Results have not been reproduced by reports from other countries participating in the study. Among 21 deaths identified, 12 were due to accidents, four were suicides, and one patient each died from pneumonia, endocrine dysfunction, primary cardiomyopathy, deficiency of humoral immunity, and coagulation defect [31]. The question of whether GHD per se is associated with an increased mortality, taking into account that pituitary produces LIF (Leukemia Inhibiting Factor) is for debate. It is strongly recommended by health authorities that hGH should be given to those who need it and the dose should be kept in the range given in the clinical trials that led to the registration of the medication [7,10,28]. 


\section{The Situation in Serbia}

Pediatric endocrinologists and pediatricians in Serbia embraced hGH use ever since its approval. We have published in 2004, Guidelines for early detection and treatment of children with congenital and acquired GHD, Turner syndrome and SGA. The publication in Serbian is result of team work, in accordance with Growth Hormone Research Society Consensus Guidelines for the treatment of GHD. Although not free of imperfections and confounders this recommendations contributed a lot in clarifying this complex area [32,33]. A plenty of periodical lectures are given, targeting pediatricians in Primary Health Care as a first line doctors, supposed to recognize and to refer short stature patients to Pediatric clinics with certified pediatric- endocrinologists. And this strategy works with regard to number of GHD children on hGH therapy in Serbia. However, the diagnosis of GHD is still made too late; in prepubertal or pubertal age. Unfortunately some short patients are referred after achievement of final heght. Data from the International Outcome Study (IOS) confirmed late referral of Serbian GHD children. The mean age at treatment start in Serbia is $11.2 \pm 3.5$ years in comparison to $8.2 \pm 4.1$ years in Czech Republic [34]. And vice versa non GHD children are often diagnosed as deficient due to reliance on $\mathrm{GH}$ provocative tests as the main diagnostic criterion of GHD [5,7]. The auxology is used as tool for detecting candidates for hGH treatment and not to establish accurate and exact diagnosis. Many clinical doctors are crossed planet due to medical tourism sponsored by hGH manufacturers; namely it is hardly to find any point, where some prescribers of hGH have never been. It is worthy to say that some of us are active in presenting Serbian results in the field all over

\section{References}

1. Bailey JD. Foreword. Clinics in endocrinology and metabolism 1982; 11:9-16

2. Rosenfield RG. Ten axioms in the evaluation of growth failure. The Endocrinologist 1997; 7:148-152.

3. Scherdel P, Dunkel L, Van Dommelen P, Goulet O, Salaun JF, Brauner, et al. Growth monitoring as an early detection tool: a systematic review. Lancet Diabetes Endocrinol 2016, http://dx doi.org/10.1016/S2213-8587(15)00392-7

4. Raben MS.Growth hormone-clinical use of growth hormone. NEJM 1962; 266:82-86.

5. Gandrud LM, Wilson DM. Is growth hormone stimulation testing in children still appropriate? Growth Horm IGF Res 2014; 14:185-194.

6. Pampanini V, Pedicelli S, Gubinelli J, Scire G, Cappa M, Boscherini B, et al. Brain magnetic resonance imaging as first-line investigation for growth hormone deficiency diagnosis in early childhood. Horm Res Paediatr 2015; 84:323-330.

7. Grimberg A, DiVall SA, Polichronakos C, Allen DB, Cohen IE, Quintos, et al. Guidelines for growth hormone and insulin-like growth factor-I treatment in children and adolescents: growth hormone deficiency, idiopathic short stature, and primary insulinlike growth factor deficiency. Horm Res Padiatr 2016; 86:361-397.

8. Argente J. Challenges in the management of short stature. Horm Res Paediatr 2016; 85: 2-10

9. Allen DB.Lessons learned from the hGH era. JCEM 2011; 96:3042-3042 the world and that it would be impossible without sponsorship [35-45]. What should be Serbian pediatric endocrinologist devoted to, in the light of new safety alerts. We must take seriously recent warnings and be engaged in raising awareness about potential short term and long term harmful effects of $\mathrm{hGH}$, with the same effort used in promotion of hGH use. At least we must inform our patients about new discoveries and to practice not only parent's informed consent, but also children's assent, as experts from Unated states and Europe suggest. Finally as mentioned above to avoid cosmetic endocrinology and to be cost-conscious of such treatment in all aspects [15,22]. We must resist to siren voices and unbearable lighteness of prescribing growth hormone. Diagnosis of short stature and its treatment is not for the amateurs. Serious lifethreatening diseases could be part of pituitary dysfunction and investigation of adrenal and thyroid axes should be the first diagnostic step. Pituitary disorders that need urgent, life-saving diagnosis are, present even at birth [46]. Cosmetic endocrinologists, obsessed with „heightism" are not involved in this process. Some of them are unfortunately only ,growth- hormonologists".

Even in this genocentric millennium nothing could replace simple and accurate height and weight measurements, staying in touch with phenotypes, clinical curiosity and honesty. Nothing compares to satisfaction get by normalization of child's growth. Growth monitoring of apparently healthy children aims at early detection of serious underlying disorders.

Acknowledgments: Supported by grants from the Ministry of Education, Science and Technological Development of Republic of Serbia No 31060, No 41018 and Internal Project No 37 of Faculty of Medicine Nis, University of Niš.

10. Allen DB. Short stature in childhood-challanges andchoises. NEJM 2013; 368:1220-1228.

11. Laventhal NT, Shuchman M, Sandberg DE. Warning about warnings: weighing risk and benefit when information is in a state of flux. Horm Res Pediatr 2013; 79:4-8.

12. De Vries MC. A tango for four: deciding on growth hormone therapy in idiopathic short stature. Horm Res Paediatr 2013; 79: 2-3

13. Campbell EG, Weissman JS, Ehringhaus S, Rao SR, Moy B, feibelman S, Goold SD. Institutional academic-industry relationships. JAMA 2007; 298:1779-1786.

14. Moynihan R, Health I, Henry D. Selling sickness: the pharmaceutical industry and disease monitoring. BMJ 2002; 324:886-891.

15. Allen DB. Growth promoting ethics and the challenge to resist cosmetic endocrinology. Horm Res Paediatr 2017; 87: 145-152

16. Adelman M. Gene test for growth hormone deficiency developped. Medicine\&health/Medical research 2018 https://medicalxpress.com/news/2018-04-gene-growth-hormonedeficiency

17. Laron Z. Extensive personal experience. Laron syndrome (primary growth hormone resistence or insensitivity): the personal experience 1958-2003. J Clin Endocrinol Metab 2004; 89:1031-1044.

18. Alatzoglou KS, Webb EA, Tissier Pl, Dattani M. Isolated growth hormonedeficiency (GHD) in childhood and adolescence. Endocrine Rev 2014; 35:376-432. 
19. Aberg D. Role of the growth hormone/insulin-like growth factor 1axis in neurogenesis. Endocr Dev 2010; 17:63-76.

20. Russo VC, Gluckman PD, Feldman EL, Werther GA. The insulinlike growth factor system and its pleiotropic functions in brain. Endocr Rev 2005; 26:916-943.

21. Allen DB. Fost NC. Growth hormone therapy for short stature: panacea or Pandora's box. J Pediatr 1990; 117:16-21.

22. Allen DB. Cost-concious growth-promoting treatment: when discretion is the better part of value. Horm Res Paediatr 2018; 90:146-150.

23. Samaras TT. We are too tall. Public Health Nutr 2009; 12: 439.

24. Samaras TT. Is height related to longevity? Life Sci 2003; 7:1781-1802.

25. Samaras TT. We are too tall (Letter to Editor). Public Health Nutrition 2017;12: 439-440.

26. Laron Z. The GH-IGF1 axis and longevity. Hormones 2008; 7:24-27.

27. Dardendeliler F, Kargiannis G, Wilton P. Headache, idiopathic intracranial hypertension and slipped capital femoral epiphysis during growth hormone treatment: a safety update from the KIGS database. Horm Res 2007; 68 Suppl 5:41-47.

28. Zadik Z. Growth hormone mortality: will history repeat itself? J Pediatr Endocrinol Metab 2012; 25:813-814.

29. Sante Adulte GH Enfant (SAGhE). http://www.afssaps.fr/Infosdesecurite/Cornmuniques-Points - presset/Hormone-de-Croissancesynthetiqu e-somatropinerecornbinante-Premiersresultats-de-1etude-epidemiologique-sur-latolerance-a-longterme-Communique. December 2010.

30. Carel JC, Ecosse E, Landier F, Meguuellati-Hakkas D, Kaguelidou $\mathrm{F}$ et al. Long-term mortality after recombinant growth hormone treatment for isolited growth hormone deficiency or childhood short stature: preliminary report of the French SAGhE study. J Clin Endocrinol Metab 2012; 97:416-425.

31. Savendahl L, Maes M, Albertsson-Wikland K, Borgström B, Carel JC, Henrard S et al. Long-term mortality and causes of death in isolated GHD, ISS, and SGA patients treated with recombinant growth hormone during childhood in Belgium, The Netherlands, and Sweden: preliminary report of 3 countries participating in the EU SAGhE study. J Clin Endocrinol Metab 2012; 97:213-217.

32. Growth Hormone Research Society; GH Research Society. Consensus guidelines for the diagnosis and treatment of growth hormone $(\mathrm{GH})$ deficiency in childhood and adolescence: summary statement of the GH Research Society. J Clin Endocrinol Metab 2000; 85:3990-3993.

33. Fraiser D. Editorial: the treatment of childhood and adolescent growth hormone deficiency-consensus or confusion?J Clin Endocrinol Metab 2000; 85:3988-3989.
34. Polak M, Konrad D, Tonnes Pedersen B, Puras G, Snajderova M. Still too little, too late? Ten years ofgrowth hormone therapy baseline data from the NordiNet International Outcome Study. J Pediatr Endocrinol Metab 2018; 31:521-532.

35. Saranac L, Zivanovic S, Radovanovic Z, Kostic G, Markovic I, Miljkovic P. Hyperprolactinaemia: different clinical expression in childhood. Horm Res Pediatr 2010; 73;187-192.

36. Saranac L, Gucev Z. New insights in septo-optic dysplasia. Prilozi 2014; 35: 123-128.

37. Saranac Lj, Stamenkovic H, Stankovic T, Zivanovic S, Djuric Z. Growth in Children with Thyroid Dysfunction. In Potlukova E Ed. Current Topics in Hypothyroidism with Focus on Development. Rijeka: InTech 2013:119-134, available from: http://www.intechopen.com/articles/show/title/growth-in-childrenwith-thyroid-dysfunction.

38. Saranac Lj, Stamenkovic H. Different Faces of Chronic Autoimmune Thyroiditis in Childhood in Adolescence. In Springer D Ed. A New Look at Hypothyroidism. Rijeka: InTech 2012; 125-132, available from: http://www.intechopen.com/ articles/show/title/different-faces-of-chronic-autoimmunethyroiditis-in-childhood-and-adolescence

39. Saranac L, Bjelakovic B, Djordjevic D, Novak M, Stankovic T. Hypopituitarism occurring in neonatal sepsis. J Pediatr Endocrinol Metab 2012; 25;847-848.

40. Saranac L, Stamenkovic H, Radovanovic Z, Kostic G, Bjelakovic B. Microprolactinoma, an unusual cause of growth hormone deficiency in a prepubertal obese boy. Inernat $\mathbf{J}$ on Disab and Develop 2005; 4:147-149.

41. Saranac L, Gucev Z. The ghrelin system; beyond the role in energy homeostasis. Facta Universitatis Series Med and Biol 2016; 18:33-38

42. Saranac L, Djuric Z, Stojsic Z, Milenovic A, Lazarevic D. Severe growth failure in a prepubertal boy: what is behind the scene? Austin J Endocrinol Diabetes 2016; 3:1046-1047.

43. Saranac L, Djuric Z, Markovic I, Stamenkovic H, Lazarevic D, Cvetkovic V. Outstanding growth response to growth hormone replacement therapy in 3 different cases of growth hormone deficiency.54th Annual ESPE 2015, 01-03 Oct Barcelona: 84

44. Saranac L, Bjelakovic B, Zivanovic S, Novak M, Markovic I, Radovanovic Z. Pituitary dysfunction types and clinical presentation of pituitary microadenomas in childhood and adolescence. 13th European Congress of Endocrinology, Rotterdam 2011, 30 Apr-04 May; 26

45. Saranac L, Novak M, Zivanovic S. Growth hormone deficiency in patients with pituitary lesions. Horm Res 2009; 72:504.

46. Scommegna S, Galeazzi D, Picone S, Farinelli E, Agostino R, Bozzao A et al. Neonatal identification for pituitary aplasia, a lifesaving diagnosis (review of five cases). Horm Res 2004; 62:10-16. 